\title{
The selective advantage of host feminization: a case study of the green crab Carcinus maenas and the parasitic barnacle Sacculina carcini
}

\author{
Tommy Kristensen • Anders Isberg Nielsen • Anders Isak Jørgensen • \\ Kim N. Mouritsen · Henrik Glenner · Jens T. Christensen · Jørgen Lützen • \\ Jens T. Høeg
}

Received: 13 April 2012/Accepted: 19 June 2012/Published online: 5 July 2012

(C) Springer-Verlag 2012

\begin{abstract}
Male crabs infected by parasitic barnacles (Rhizocephala) are known to be morphologically feminized. Here, we investigate morphological chances in green crabs, Carcinus maenas, induced by the parasitic barnacle Sacculina carcini. Infected males acquire a broader, longer and segmented abdomen, fringed with marginal setae. Copulatory appendages and pereopods are reduced in length, and the chelae become smaller. The feminization show great individual variation. Males with scars from lost externae, the parasites reproductive organ situated under the abdomen, are less modified than males carrying an externa, and the feminization is more pronounced in smaller than in larger males. No super-feminization is evident in female crabs that remain morphologically unaffected by infection. The protective value of a parasitically induced enlargement of the male abdomen may constitute an adaptation that increases parasite longevity. The additional effects on male morphology are viewed as pleiotropic side effects of the main adaptive value of enlarging the abdomen.
\end{abstract}

Communicated by S. A. Poulet.

T. Kristensen · J. Lützen · J. T. Høeg

Department of Biology, Section for Marine Biology,

Copenhagen University, Universitetsparken 4,

2100 Copenhagen, Denmark

A. I. Nielsen · A. I. Jørgensen · K. N. Mouritsen ( $₫)$.

J. T. Christensen

Department of Bioscience, Marine Ecology, Aarhus University,

Ole Worms Allé 1, 8000 Aarhus C, Denmark

e-mail: kim.mouritsen@biology.au.dk

H. Glenner

Department of Biology, Biological Institute, University

of Bergen, Thormøhlsgae 55, 5020 Bergen, Norway

\section{Introduction}

The way rhizocephalan barnacles influence their crustacean hosts has elicited considerable interest, since Giard (1886) discovered that males of the spider crab Macropodia rostrata L., 1758, parasitized by the sacculinid Drepanorchis neglecta Fraisse, 1877, adopted a number of feminine traits, in particular a broadened abdomen. In female crabs, the abdomen covers and protects the egg mass of the gravid crab and, if parasitized by D. neglecta, the external reproductive apparatus, the externa, of the parasite. Male crabs have narrow abdomens that fit in a groove of the thoracic sternum of the crab like a key in a lock. Infected male crabs develop abdomens as broad as females that provide the same degree of protection to the parasite as is normally offered to the brood. Since Giard's discovery, it has become clear that all studied brachyuran hosts parasitized by species of the family Sacculinidae become morphologically modified, sterilized and subjected to physiological and behavioural changes (Høeg and Lützen 1996; Høeg 1996). As a rule, males are much more heavily influenced than females and may be feminized to such a degree that on a superficial view they become almost indistinguishable from the opposite sex. In most cases, sacculinized females undergo no morphological changes.

Sacculina carcini Thompson, 1836, parasitizes a great number of portunid crab species (Høeg and Lützen 1985; $\emptyset$ ksnebjerg, 2000). There are several reports on how it influences its host morphologically, but some of them pertain to another species of Sacculina, S. benedeni Kossmann, 1872 (Bulgurkov 1938; Vernet-Cornubert 1958). Day (1935) studied the way S. carcini influences Liocarcinus holsatus (Fabricius, 1798) while Veillet (1945) examined the modifications inflicted by S. carcini 
on the estuary crab, Carcinus aestuarii Nardo, 1847. From these studies, it is apparent that the degree each individual $S$. carcini parasite exerts on its host is much more variable than the non-or-all effect observed in D. neglecta. This applies in particularly to how $S$. carcini modifies its classical host, the green crab Carcinus maenas, where the abdominal morphology of an infected male crab ranges from almost no modifications to an appearance approximating that of an adult female (present study). This variation of a parasite-induced host character of potential importance for the survival of the parasite provides an excellent chance for studying a morphological trait under possible Darwinian selection. Hence, as part of a 3-year study of the biology and parasites of the green crab, we embarked on a large-scale field study on how C. maenas is morphologically affected by $S$. carcini. In particular, it was decided to investigate to what extent a feminized host abdomen is of selective advantage for the parasite.

\section{Materials and methods}

Field sampling and measurements

In total, 366 uninfected and 249 sacculinized green crabs were included in the study, all collected at four localities in Limfjorden, Denmark. Limfjorden is a major but shallow waterway (depth typically 4-6 m) that traverses the northern part of Jutland connecting the North Sea with the Kattegat/Baltic Sea estuary. The salinity varies from c. 31 psu in the west to c. 23 psu in the east, with bottom temperatures between $18^{\circ} \mathrm{C}$ in July-August and $1-2{ }^{\circ} \mathrm{C}$ in February-March. The green crabs occur at all depths and all over the fjord, while $S$. carcini in some years may be absent from some of the eastern less saline areas.

Crabs were caught in baited traps at three localities: Venø Bay, off Bjørndrup and Lovns Broad (May-August 2009; depths: 1-6 m; salinity: 28-31 psu, 22-29 psu and 22-25 psu, respectively). Crabs from a fourth locality, off Rønbjerg harbour, were collected in fish traps (26 June-2
July 2006; $2 \mathrm{~m} ; 26 \mathrm{psu}$ ). The majority of the crabs was above $30 \mathrm{~mm}$ in carapace width and therefore considered mature. Six types of crabs were distinguished: apparently non-parasitized males and females, parasitized males and females with externae of Sacculina carcini, and parasitized male and female crabs with scars from externae that had been lost. Only few sacculinized female crabs were caught at Rønbjerg, and thus, the analyses of these data focus solely on males and non-infected females. The abdomens of all crabs were lifted from the thorax to inspect them for infestation (presence of externa or scar). To verify that all apparently non-infected crabs were indeed uninfected, the crabs from Lovns Broad, Venø Bay and Bjørndrup were dissected for presence of an internal root system. The noninfected crabs used for comparison were chosen randomly, and damaged specimens were discarded. The number and infection status of crabs used in the study are found in Table 1 . Besides the externally sacculinized crabs, a number of males with broader abdomens than usual were found. When dissected, those crabs were found to contain rhizocephalan rootlets. Such crabs were also noted by Day (1935), who explained them as sacculinized males that had lost their externae and moulted again, and by Werner (2001), who considered them parasitized males, the externa of which had not yet emerged. In the present study, these males were excluded from the analysis.

The following characters were measured on the collected green crabs: (1) carapace width $(\mathrm{CW})$ defined as the distance between the fifth pair of lateral spines (Fig. 1a); (2) maximum width of abdominal segment 3,5 and 6 (Fig. 1b-d); (3) maximum length of abdominal segment 6 (Fig. 1b-d); (4) distance from base to tip of the left first pair of pleopod of males (copulatory appendage) (Fig. 1f); (5) height of the right claw from the dorsal notch near the base of movable finger to the ventral margin (Fig. 1g); (6) length of left and right pereopod 3 (second walking leg) from base to tip (Fig. 1h). Data from solely the longer of the two measured pereopods were used in the analysis. Carapace width and pereopod length were measured by ruler to the nearest $\mathrm{mm}$, whereas the remaining characters were measured to the nearest $0.1 \mathrm{~mm}$ using a dissection

Table 1 The total material studied distributed on sampling location and gender of the host, green crab Carcinus maenas

\begin{tabular}{|c|c|c|c|c|c|c|}
\hline \multirow[t]{2}{*}{ Location } & \multicolumn{3}{|l|}{ Males } & \multicolumn{3}{|l|}{ Females } \\
\hline & Uninfected & With externa & With scar & Uninfected & With externa & With scar \\
\hline Lovns Broad $\left(56^{\circ} 38^{\prime} 4^{\prime \prime} \mathrm{N}, 9^{\circ} 13^{\prime} 3^{\prime \prime} \mathrm{E}\right)$ & 49 & 0 & 0 & 0 & 0 & 0 \\
\hline Bjørndrup $\left(56^{\circ} 49^{\prime} 25^{\prime \prime} \mathrm{N}, 8^{\circ} 51^{\prime} 41^{\prime \prime} \mathrm{E}\right)$ & 0 & 17 & 16 & 2 & 13 & 0 \\
\hline Ven $\varnothing$ Bay $\left(56^{\circ} 34^{\prime} 28^{\prime \prime} \mathrm{N}, 8^{\circ} 40^{\prime} 39^{\prime \prime} \mathrm{E}\right)$ & 0 & 54 & 29 & 88 & 34 & 2 \\
\hline Rønbjerg $\left(56^{\circ} 53^{\prime} 28^{\prime \prime} \mathrm{N}, 9^{\circ} 9^{\prime} 49^{\prime \prime} \mathrm{E}\right)$ & 118 & 84 & 0 & 109 & 0 & 0 \\
\hline
\end{tabular}

Uninfected: non-sacculinized crabs; with externa: sacculinized crabs possessing an externa; with scar: sacculinized or previously sacculinized crabs with scar after lost externa 


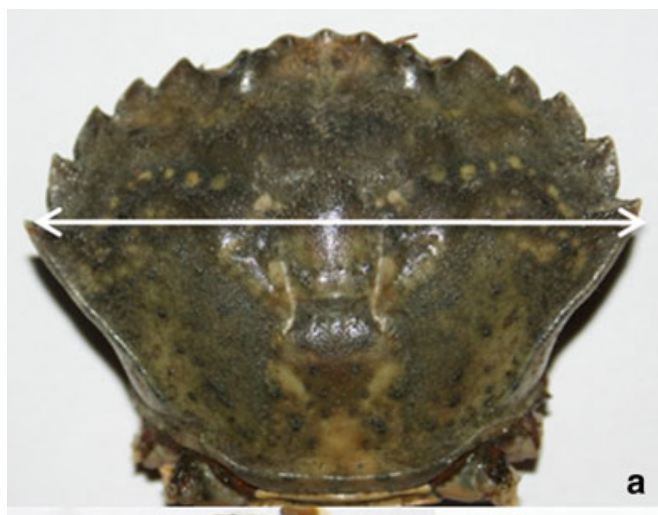

d

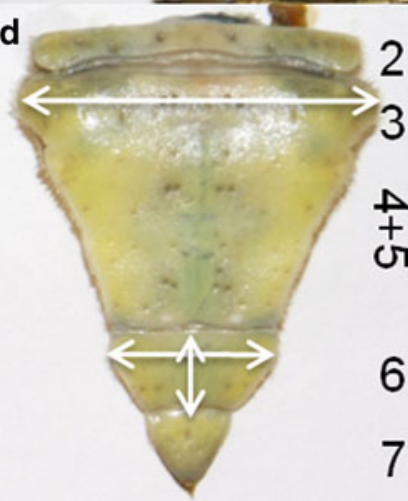

Fig. 1 Morphological characters and measures taken on uninfected and sacculinized green crabs Carcinus maenas. a Dorsal view of carapace. Dorsal view of abdomen of non-infected female (b) infected male with marginal setae (c) and non-infected male (d). e Ventral
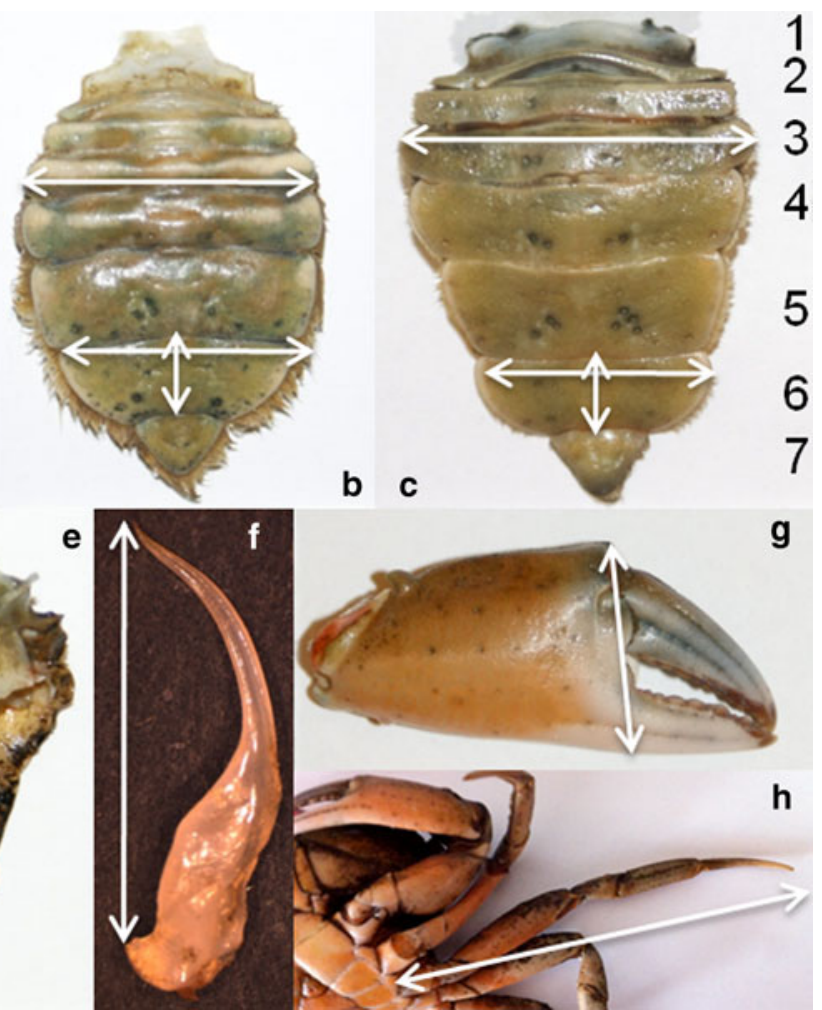

view of infected but unmodified male with scar from lost externa (white arrow). f Copulatory appendage (pleopod 1). g Claw. h Pereopod 3 (second walking leg). The double-arrows show distances measured. Not to scale; see text for details

consists of numerous connected tubular and semitransparent rootlets embedded in the host tissue.

\section{Data analyses}

The data analysis was carried out using IBM SPSS 19.0 (one-way analyses) and SMATR 2.0 (regressions and ANCOVA). In those instances where data did not meet the prerequisites of parametric tests (normality, homogeneity of variance), data were either transformed prior to analysis or nonparametric tests were applied. All performed post hoc tests are corrected for multiple comparisons.

Crabs from Rønbjerg were analysed separately by expressing all measured characters as a function of $\mathrm{CW}$ in analyses of covariance comparing the three main groups of crabs in question: infected males, uninfected males and uninfected females. This was done because the Rønbjerg animals (1) were collected at a single site within a narrow time span and depth (low variance), (2) included a relatively large number of individuals from all of the three main crab groups (see Table 1) (high statistical power) and (3) were not measured for the width of segment 3 (invalidating RAW calculation, and hence, one-way analyses). 


\section{Results}

Abdominal morphology

The relative abdominal width (RAW) of crabs from Ven $\varnothing$ Bay, Bjørndrup and Lovns Broad combined, differed according to infection status and gender (Fig. 2a). The RAW of externally sacculinized males (externae present) was significantly smaller (i.e. having broader abdomen; on average $11.1 \%$ ) than that of uninfected males (Fig. 1c-d), whereas scarred sacculinized males (Fig. 1e) attained intermediate RAW values. In an analysis including also female categories, scarred males were statistically similar to the remaining male categories (Fig. 2a). Considering solely males in a separate analysis, all three male categories could be separated statistically (Kruskal-Wallis test, $\chi_{2}^{2}=65.73, P<0.0005$; post hoc test: $P \in[<0.0005$; 0.044]). Hence, scarred males have a slightly narrower abdomen than males with externae, but also a broader abdomen than non-infected males. Females on the other hand attained a similar RAW regardless of infection status and always had a broader abdomen than any male (Fig. 2a). For all three male categories, there was no significant relationship between RAW and carapace width (Linear regression; $r^{2}<0.054, P>0.054$ ). In contrast, the RAW of non-infected females was negatively related to carapace width $\left(r^{2}=0.325, P<0.0005\right)$ as was the case also for infected females (scarred and with externae) within the same size range as non-infected females $\left(r^{2}=0.107\right.$, $P=0.030)$. Hence, regardless of infection status, the relative abdominal width (RAW) increases with size/age in female crabs, but not in males.

In the Rønbjerg sample, the width of the sixth abdominal segment as a function of carapace width (Fig. 1a-d) was used to analyse the parasite-induced abdominal broadening in male crabs. Width of segment 6 increased linearly with carapace width for non-infected females, noninfected males and infected males, albeit at a significantly higher rate in females than in males irrespective of the infection status of the latter [Fig. 3a; equality of slope among groups: Standardized Major Axis (SMA) analysis, $T=200.78, P<0.0005$; post hoc test: females versus male groups, $P=0.0001]$. But whereas the slope of infected and non-infected males was similar (post hoc test, $P=0.687$ ), suggesting similar metric modification regardless of size/age, infected males generally attained a broader abdomen than non-infected (by $12.4 \%$ based on grand means) (Fig. 3a; equality of grand means: SMA on square-root transformed data, Wald test, $W_{1}=223.39$, $P<0.0005)$. Similar results were obtained also for the width of the fifth abdominal segment (data not shown), suggesting that infection results in a broadening of the entire abdomen. Not only the width but also the length of
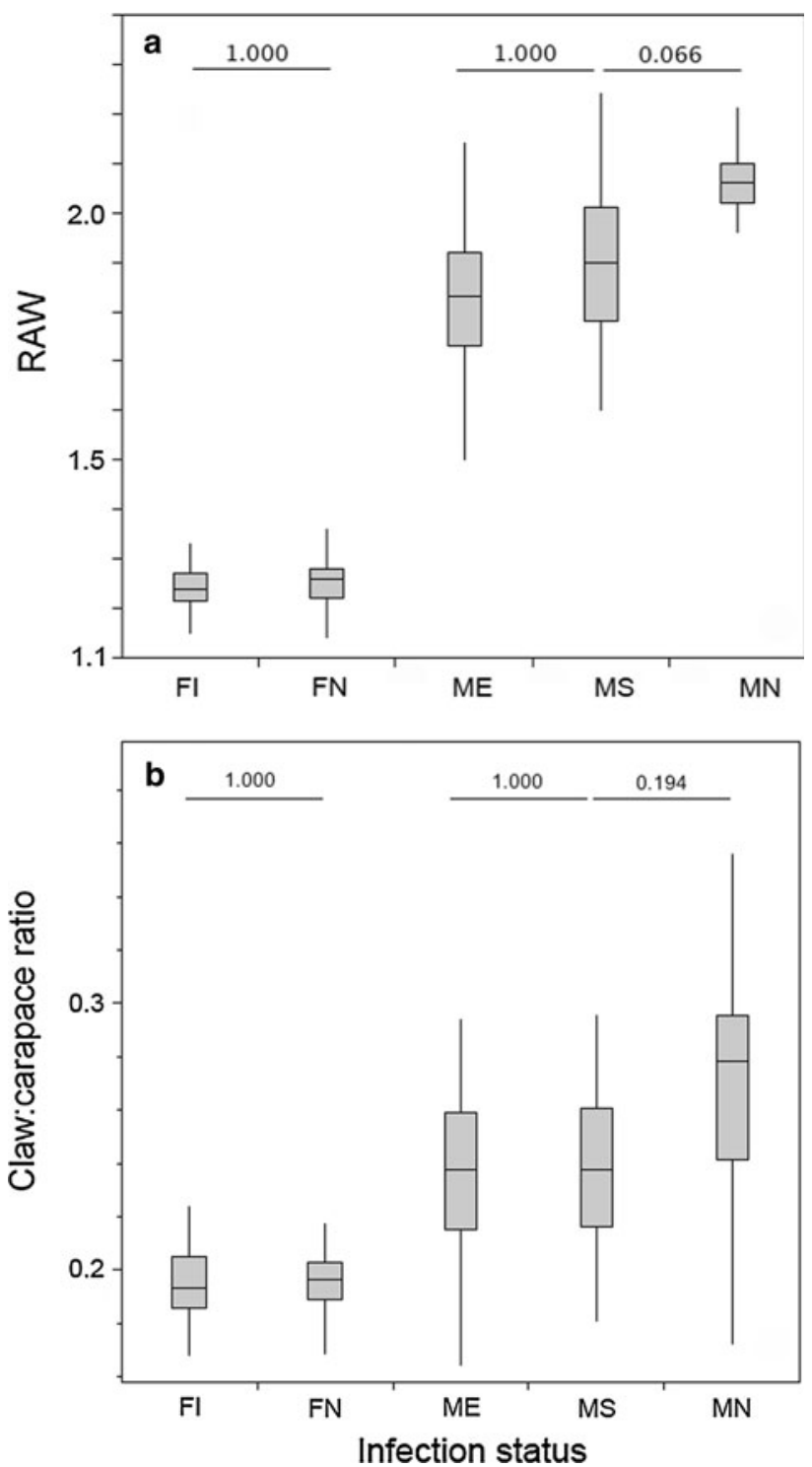

Fig. 2 Abdominal and claw dimension of infected and uninfected Carcinus maenas from Venø Bay, Bjørndrup and Lovns Broad combined. a Box-plot (mean, SE, range) of relative abdominal width (RAW) of infected females with externae or scar $(F I, n=49)$, noninfected females $(F N, n=90)$, infected males with externae $(M E$, $n=71)$, infected males with scars $(M S, n=45)$ and non-infected males $(M N, n=49)$. Median RAW differs significantly among infection status categories (Kruskal-Wallis test, $\chi_{4}^{2}=245.59$, $P<0.0005)$. Lines above box-plots connect statistically similar categories according to post hoc test correcting for multiple comparisons ( $P$ values given). All other pair-wise comparisons demonstrated significantly different RAW $(P<0.0005)$. b Box-plot (mean, SE, range) of the claw:carapace ratio (claw height divided by carapace width). Sample sizes and category abbreviations: see above. Median claw:carapace ratio differs significantly among categories (KruskalWallis test, $\left.\chi_{4}^{2}=151.239, \quad P<0.0005\right)$. Lines above box-plots connect statistically similar categories according to post hoc test correcting for multiple comparisons ( $P$ values given). All other pairwise comparisons demonstrated significantly different claw:carapace ratios $(P<0.022)$ 

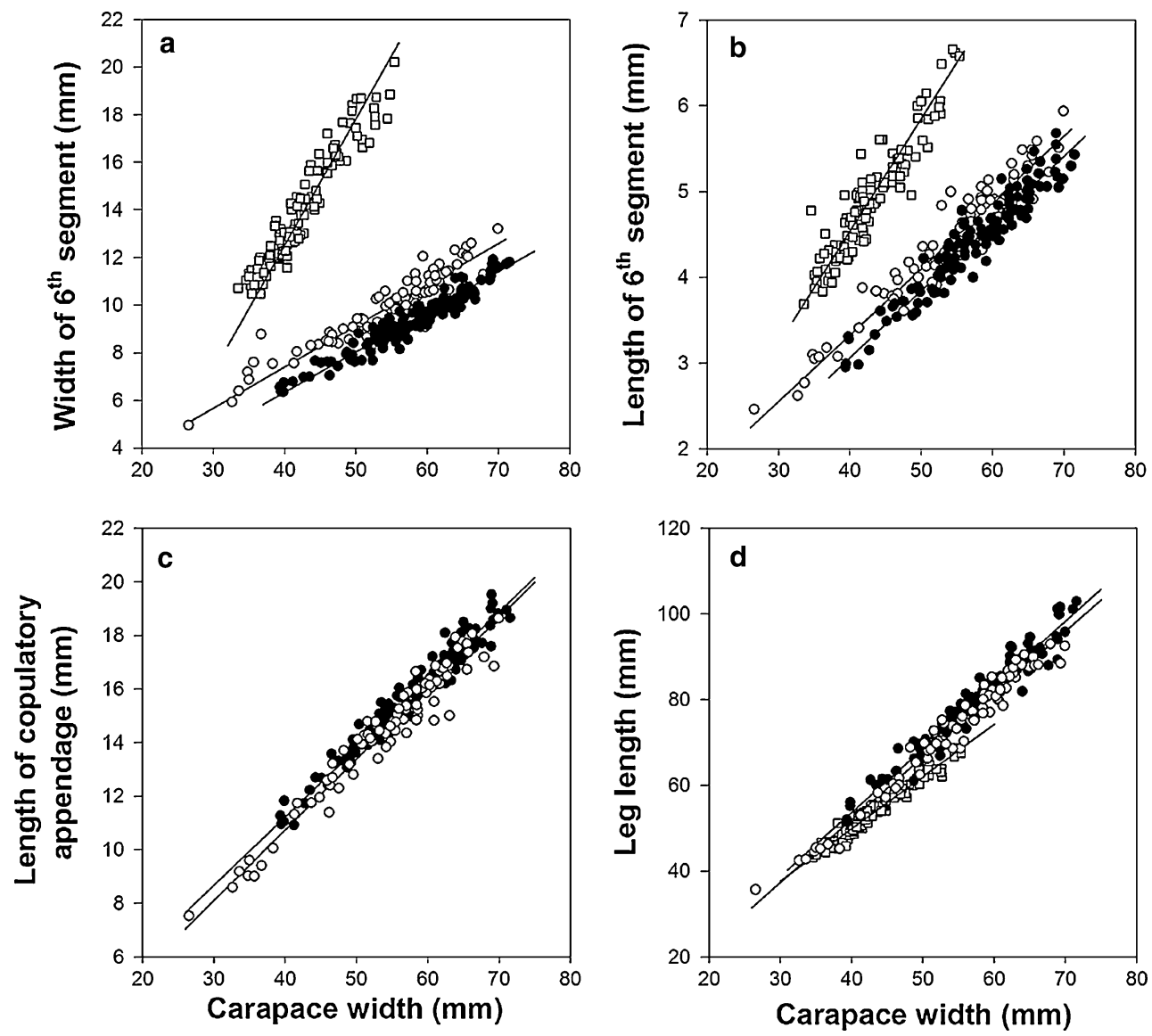

Fig. 3 Dimensions of abdomen, copulatory appendages and peropods (legs) as a function of carapace width (CW) in infected and uninfected Carcinus maenas from Rønbjerg. a Standardized Major Axis (SMA) analysis of the width of the sixth abdominal segment for infected males (open circle; $n=84 ; \quad y=0.173 x+0.498 ; \quad r^{2}=0.860$, $P<0.0005)$, non-infected males (closed circle; $n=118$; $\left.y=0.169 x-0.432 ; \quad r^{2}=0.922, \quad P<0.0005\right)$ and non-infected females (open square; $n=109 ; y=0.530 x-8.687 ; r^{2}=0.673$, $P<0.0005$ ). b Standardized Major Axis (SMA) analysis of the length of the sixth abdominal segment for infected males (open circle; $\left.n=84 ; y=0.173 x+0.498 ; r^{2}=0.860, P<0.0005\right)$, non-infected males (closed circle; $n=118 ; y=0.169 x-0.432 ; r^{2}=0.922$, $P<0.0005$ ) and non-infected females (open square; $n=109$;

the abdomen of males increases following infection. As is the case for the width, the length of the sixth abdominal segment increased linearly with carapace width for all three analysed groups of crabs, albeit at a significantly higher rate in females than in the two male groups (Fig. 3b; equality of slope among groups: SMA, $T=113.20$, $P=0.0001$; post hoc test: females versus male groups, $P=0.0001)$. Whereas the slope of infected and noninfected males was similar (post hoc test, $P=0.739$ ), infected males generally attained a longer sixth abdominal segment than non-infected (by $5.8 \%$ based on grand means) (Fig. 3b; equality of grand means: SMA, Wald test, $\left.W_{1}=75.34, P<0.0005\right)$. Hence, the abdomen of $\left.y=0.530 x-8.687 ; r^{2}=0.673, P<0.0005\right)$. c. Standardized Major Axis (SMA) analysis of the length of the copulatory appendage (pleopod 1) for infected males (open circle; $n=84$; $\left.y=0.264 x+0.187 ; \quad r^{2}=0.949, \quad P<0.0005\right)$ and non-infected males (closed circle; $n=117 ; y=0.255 x+1.017 ; r^{2}=0.953$, $P<0.0005)$. d. Standardized Major Axis (SMA) analysis of the length of the longest third pereopod (second walking leg) for infected males (open circle, $n=77 ; \quad y=1.47 x-6.551 ; \quad r^{2}=0.969$, $P<0.0005), \quad$ non-infected males (closed circle; $n=107$; $\left.y=1.49 x-5.796 ; \quad r^{2}=0.949, \quad P<0.0005\right)$ and non-infected females (open square; $n=100 ; \quad y=1.22 x+1.16 ; \quad r^{2}=0.961$, $P<0.0005)$

sacculinized males is generally morphologically feminized, but, in a male way: infected males do not adopt the inherent allometric relationship characteristic of females.

Accompanying these abdominal changes of sacculinized males, the usually fused third to fifth segments (Fig. 1d) develop an articulation, although they never become capable of independent movements as in females. In addition, many of the sacculinized males acquired shorter or longer setae along the margin of the abdomen as females also possess (Fig. 1b, c). However, in not a single case did they develop any trace of the setose pleopods 2-5 characteristic for females. The morphology of these pleopods also appeared unaffected by infection in females. 
Male copulatory appendages

In the combined Venø Bay, Bjørndrup and Lovns Broad samples, the length of the first pair of the copulatory appendages was positively related to carapace width in all three male categories: non-infected, scarred and externae present (Linear regression, $r^{2}>0.809, P<0.0005$ ). Corrected for carapace width (i.e., the appendage:carapace ratio), there was no statistically significant effect of infection status on the relative size of these appendages (One-way ANOVA, $F_{2,159}=2.099, P=0.126$ ). An SMA analysis of the Rønbjerg data demonstrated a small but significant length reduction in the copulatory appendages of infected individuals (2.2\% based on grand means) (Fig. 3c; equality of slope: $T=1.115, P=0.296$; equality of grand means: Wald test, $W_{1}=21.402, P<0.0005$ ). However, the morphology of the appendages seemed unaffected.

\section{Claw dimensions}

In the combined Venø Bay, Bjørndrup and Lovns Broad samples, claw height (Fig. 1g) was positively related to carapace width in all investigated crab categories (Linear regression, $\left.r^{2}>0.638, P<0.0005\right)$. Corrected for carapace width (i.e., claw:carapace ratio), relative claw height was significantly affected by gender and male infection status (Fig. 2b). Infected and uninfected females had similar sized claws that were significantly smaller than those of males irrespective of their infection status. Sacculinized male crabs possessing an externa expressed a significantly smaller claw:carapace ratio than non-infected males, thereby approaching the claw dimensions of females. In an analysis including also the female categories, scarred males could not be statistically separated from either non-infected males or males with externae (see Fig. 2b). But a separate analysis including solely the three male categories suggests that the relative claw size of scarred males is similar to those with externae, but significantly smaller than those of non-infected males (Kruskal-Wallis test, $\chi_{2}^{2}=22.392$, $P<0.0005$. Post hoc test: scarred versus externae, $P=1.000 ;$ scarred versus non-infected, $P<0.0005$ ). Hence, infection by Sacculina in males results in a claw size intermediate between non-infected males and females.

\section{Pereopod length}

In the Rønbjerg sample, the length of the longer third pereopod (Fig. 1h) increased linearly with carapace width for non-infected females, non-infected males and infected males, albeit at a significantly lower rate in females than in males irrespective of infection status of the latter (Fig. 3d; equality of slope among groups: SMA, $T=51.844$,
$P=0.0001$; post hoc test: females versus male groups, $P=0.0001)$. Whereas the slope of infected and non-infected males was similar (post hoc test, $P=0.604$ ), infected males generally attained shorter pereopods $(8.1 \%$ shorter based on grand means) than non-infected males (Fig. 3d; equality of grand means: SMA, Wald test, $W_{1}=28.76$, $P<0.0005)$. Thus, as for the abdomen, the walking legs of sacculinized males are morphologically feminized, but without adopting the inherent female allometry.

\section{Discussion}

Modification of male crabs

Most male $C$. maenas parasitized by $S$. carcini showed a modification of secondary sexual characters which can be summarized as follows: a redivision of the abdomen, which broadens to various degrees albeit rarely to an extent comparable to that of healthy females (Figs. 2a, 3a); sacculinized males acquire marginal setae on the abdomen (Fig. 1c); the length of the abdomen, as expressed by the sixth segment (Fig. 3b), shows a slight increase which, in companion with the increase in width, results in an overall larger abdomen; a slight diminution of the copulatory appendages (expressed by pleopod 1, see Fig. 3c); and no additional pleopods appear. The claws show the highest degree of modification, since they often tend to approximate those of normal females of same size (Fig. 2b). Finally, the walking legs are reduced in length as expressed by the third pereopods (Fig. 3d), thereby approaching the relatively shorter female pereopods. These results largely agree with those of Potts (1909), Foxon (1940) and Werner (2001), who studied the same association but only considered the modification in abdominal shape, and also those of Day (1935), who examined males of L. holsatus parasitized by $S$. carcini. As described by Veillet (1945), $S$. carcini causes much more modification of males when parasitizing $C$. aestuarii, a sibling species of $C$. maenas found in the Mediterranean. These modifications comprise a resegmentation of the abdomen, which may become nearly as broad as in sexually mature females, acquisition of pronounced marginal setae, and appearance of femalelike biramous and setae pleopods (swimmerets) that often become asymmetrically developed. The copulatory appendages become shorter and more fragile, and the second pleopod disengages from the first and may acquire segmentation and setae. The claws also diminish in size. Nielsen (1970) similarly observed that the modification of males caused by hermit crab infesting rhizocephalans may vary with host species.

Even more extensive modification of sacculinized males occur in other species of crabs parasitized by sacculinid 
rhizocephalans. Infested males not only may acquire an abdomen as broad and vaulted as in the female counterpart, but may also show a varying number of pleopods, degeneration or disappearance of the copulatory appendages, and reduction in the size of the chelae (Giard 1886; Smith 1910; Okada and Miyashita 1935; Matsumoto 1952; George 1959; Galil and Lützen 1995). The almost total feminization of Portunus sanguinolentus (Herbst, 1783) by Heterosaccus ruginosus Boschma, 1931, led Nair and Gurumani (1956) and Srinivasagam (1982) to believe that each of the 179 sacculinized crabs investigated were of the female sex. This highlights the importance of taking parasitic feminization into account in population studies of sacculinized crab populations.

Several studies have shown that the degree to which male hosts become modified decreases with size (Pérez 1933; Day 1935; Veillet 1945). The explanation given for this is that the modifications occur stepwise and at each moult and that smaller crabs on an average go through more moults than larger ones before the cessation of moulting caused by the parasite sets in. Our data support this explanation because our analyses of covariance disclose that smaller sacculinized male crabs are relatively more modified than larger males (Fig. 3). This agrees with the observations made by Foxon (1940), but is contrary to those of Potts (1909), two authors who studied the same parasite-host association as we did. These covariance analyses also suggest that the amount of modification in exact metric terms to be similar in infected males regardless of their size.

\section{Modification of female crabs}

Parasitized females of $C$. maenas did not exhibit any morphological modification. The mean relative abdominal width and the claw size remain unchanged (Fig. 2). This is concordant with most other studies showing that sacculinized females undergo little, if any, modifications (Day 1935; Hartnoll 1967; Phillips and Cannon 1978; Yamaguchi and Aratake 1997; Werner 2001). Nevertheless, some crabs, including $C$. aestuarii parasitized by $S$. carcini, may be subject to major changes (Veillet 1945). Although such cases are deceptively known as hyperfeminization, the abdomen is usually of normal width and only rarely excessively broadened as seen, for instance, in Callinectes sapidus Rathbun, 1896, parasitized by Loxothylacus texanus Boschma, 1933 (Reinhard 1950). Moreover, rather than increasing in size, the pleopods may degenerate more or less completely (Okada and Miyashita 1935; Matsumoto 1952; Galil and Lützen 1995). In female crabs of some species, the adult secondary sexual characters may appear at a considerable smaller body size than usual as a result of sacculinization (Smith 1906, 1910; Pérez 1933; Veillet
1945; Vernet-Cornubert 1958). In the very few cases where the relative claw size in sacculinized females has been analysed, it never differs from that of non-parasitized females (Veillet 1945; Yanagimachi and Aratake 1997).

\section{Survival of externae on modified crabs}

Veillet (1945) and Lützen (1984) showed that the ratio of externally infected female crabs to that of the males gradually increases with the age of the externae. In our presently unpublished material, comprising more than 17,000 parasitized $C$. maenas from Limfjorden, the proportion of infected male crabs with scars from lost externas is $23.8 \%$, while the same proportion for female crabs is only $14.6 \%$. Together, this suggests that females are better hosts. The much broader abdomen of the female, particularly in the larger individuals having relatively broader abdomen, offers a better protection of the externa than the narrower abdomen of males. Regeneration of a lost externa occurs only rarely in S. carcini (Lützen 1981). Externa loss usually leads to the death of the parasite. This means that the survival rate of the parasite is favoured by the development of a broad female-like abdomen that protects against accidental and loss of the externa. In the sacculinid Heterosaccus dollfusi Boschma, 1960, the parasite induces an abdomen as broad as that of healthy females of its host Charybdis longicollis Leene, 1938. This results in an equally high survival of the externae in both host sexes (Galil and Lützen 1995). This is born out by the fact that the number of scarred crabs, each indicating a lost externa, makes out only $2.3 \%$ of the number of crabs with externae, a percentage that is much lower than in most other species of sacculinized crabs (Veillet 1945; Lützen 1984). This probably means that most externae of $H$. dollfusi stay with the host for life and are rarely lost. In Portunus pelagicus L., 1758, sacculinized males develop an abdomen almost as broad as that of the females, and the percentage of scarred males is accordingly also low, $<1 \%$ (Weng 1987). Our data on S. carcini infesting C. maenas show a more variable pattern. In contrast to the examples mentioned above, the degree to which $S$. carcini modifies the abdomen of a male host varies greatly from one host specimen to another; from almost no change to close to female proportions (Figs. 1, 2, 3). The data furthermore demonstrate that crabs with scars from lost externae show significantly less pronounced feminization of the abdomen than found in males, still carrying viable externae (Fig. 2a). This may reflect the presence of a co-evolutionary arms race scenario between host and parasite: a parasite unable to cause a male host to produce a protectively broadened female-like abdomen is selected against. The host, on the other hand, is exposed to strong selection pressure to prevent the parasite-induced broadening of the abdomen. The 
less morphological affected an infected male host, the greater is the chance that the emerging externa is physically damaged and dies due to the poor protection provided by a narrow male abdomen. The death of the parasite might enable the crab to resume moulting and eventually reproduce. In contrast to the sacculinids on $C$. longicollis and $P$. pelagicus, where this arms race seems already won by the parasite, the $S$. carcini/C. maenas system may be at a transitional evolutionary state, where full feminization of the abdomen in male hosts has been only partly established. As a result, the capability of each individual parasite to modify the host still varies greatly within the population. This calls for experimental studies on the extent to which $C$. maenas that loose a $S$. carcini externa resume growth and reproduction. Although scarred $C$. maenas have a higher mortality rate than uninfected crabs, they may survive for an extended period of time (Lützen 1981). The additional parasitically induced morphological effects on the male (reduced copulatory appendages, chelae and pereopods) cannot easily be interpreted as advantageous to parasite survival. They may simply be pleiotropic side effects from the main adaptive value of broadening the abdomen through hormonal manipulation. However, possibly also less understood physiological or behavioural advantages of feminizing male hosts could be involved.

\section{Phylogenetic remarks}

Species of the family Sacculinidae Lilljeborg, 1860, exhibit a number of surprisingly uniform morphological traits. Attached to the underside of the brachyuran host's abdomen, the left and right sides of the externa are flattened to fit into the narrow space between the sternum and the abdomen, with the dorsal sides and ventral sides always directed towards the same sides with respect to the host's abdomen. Molecular data have nevertheless shown the family and the type genus Sacculina Thompson, 1836, to be diphyletic (Glenner and Hebsgaard 2006). To date, few species of Sacculina have been relegated to the Sacculinidae s. str., which besides the type species, S. carcini, probably contains all species of Heterosaccus Smith 1906 and Loxothylacus Boschma, 1928. No family name has yet been proposed for the other group, which is known with certainty to contain only a few species that were earlier referred to as Sacculina plus all three species of Polyascus Glenner, Lützen and Takahashi, 2003.

When comparing morphological modifications caused by sacculinid and non-sacculinid species of the "Sacculinidae", the general pattern is the same: males invariable acquire a broadened and resegmentated abdomen, which may or may not develop pleopods, and the copulatory appendages may degenerate while the claws almost always become reduced in size. The females, in contrast, are rarely affected. The underlying physiological cause of the feminization of parasitized males is still unknown. It has been explained as a parasitic destruction of the androgenic gland, which in healthy crabs induces masculinisation in the males (Veillet and Graf 1958; Høeg 1995), but alternative physiological pathways might be possible. In any case, it is most likely that the mechanism operating in both groups of 'sacculinids' is identical.

Acknowledgments We are very grateful to the Carlsberg Foundation for covering all expenses connected with the study (grant no. 2008-01-0491). We also wish to thank the staff of the Danish Shellfish Center, Nykøbing Mors, Denmark, for collecting some of the material and providing laboratory facilities, and Dr. David R. Nash, Section for Social Evolution, Department of Biology, University of Copenhagen, Denmark, for advice and assistance.

\section{References}

Bulgurkov K (1938) Study of Rhizocephala and Bopyridae from the Bulgarian Black Sea coast. Trudy na Chernorskata Biol Sta. v'Varna 7:69-81

Day JH (1935) The life-history of Sacculina. Q J Microsc Sci 77:549-583

Foxon GEH (1940) Notes on the life history of Sacculina carcini Thompson. J Mar Biol Assoc UK 24:253-264

Galil BS, Lützen J (1995) Biological observations on Heterosaccus dollfusi Boschma (Cirripedia: Rhizocephala), a parasite of Charybdis longicollis Leene (Decapoda: brachyura), a lessepsian migrant to the Mediterranean. J Crust Biol 15:659-670

George AI (1959) Heterosaccus ruginosus (Boschma), a rhizocephalan parasite of the crab Neptunus sanguinolentus (Herbst). J Zool Soc India 11:171-204

Giard A (1886) De l'influence de certains parasitès rhizocéphales sur les caractères sexuels extérieures de leur hôte. C R Hebd Acad Sci 103:84-86

Glenner H, Hebsgaard MB (2006) Phylogeny and evolution of life history strategies of the parasitic barnacles (Crustacea, Cirripedia, Rhizocephala). Mol Phylogenet Evol 41:528-538

Hartnoll RG (1967) The effects of sacculinid parasites on two Jamaican crabs. J Linn Soc (Zool) 46:275-295

Høeg JT (1995) The biology and life cycle of the Rhizocephala (Cirripedia). J Mar Biol Assoc UK 75:517-550

Høeg JT, Lützen J (1985) Crustacea Rhizocephala. Marine invertebrates of Scandinavia 6. Norwegian University Press, Oslo, pp 1-92

Lützen J (1981) Field studies on regeneration in Sacculina carcini Thompson (Crustacea: rhizocephala) in the Isefjord, Denmark. J Exp Mar Biol Ecol 53:241-249

Lützen J (1984) Growth, reproduction and life span in Sacculina carcini Thompson (Cirripedia: rhizocephala) in the Isefjord, Denmark. Sarsia 69:91-106

Matsumoto K (1952) On the sacculinization of Charybdis japonioca (A. Milne-Edwards). Biol J Okayama Univ 1:84-89

Nair NB, Gurumani ON (1956) On the occurrence of three Sacculina parasitising the edible crab Neptunus sanguinolentus. J Bombay Nat Hist Soc 53:730-732

Nielsen S-O (1970) The effects of the rhizocephalan parasites Peltogaster paguri Rathke and Gemmosaccus sulcatus (Lilljeborg) on five species of paguridan hosts (Crustacea: decapoda). Sarsia 42:17-32

Okada YK, Miyashita Y (1935) Sacculinization in Eriocheir japonicus de Haan, with remarks on the occurrence of complete sex- 
reversal in parasitized male crabs. Mem Col Sci Kyoto Imp Univ B 10:169-208

Øksnebjerg B (2000) The Rhizocephala (Crustacea: cirripedia) of the Mediterranean and Black Seas: taxonomy, biogeography, and ecology. Israel J Zool 46:1-102

Pérez C (1933) Action de la sacculine sur les caractères sexuels extérieures du Pachygrapsus marmoratus. C R Soc Biol Paris 113:1027-1029

Phillips WJ, Cannon LRG (1978) Ecological observations on the commercial sand crab, Portunus pelagicus (L.), and its parasite, Sacculina granifera Boschma, 1973 (Cirripedia: rhizocephala). J Fish Dis 1978:137-149

Potts FA (1909) Observations on the changes in the common shorecrab caused by Sacculina. P Camb Philos Soc 15:96-100

Reinhard EG (1950) An analysis of the effects of a sacculinid pasrasite on the external morphology of Callinectes sapidus Rathbun. Biol Bull Wood's Hole 98:255-288

Smith G (1906) Rhizocephala. Fauna Flora Golf Neapel 29:1-123

Smith G (1910) Studies in the experimental analysis of sex. Part 3. Further observations on parasitic castration. Q J Microsc Sci $55: 225-240$

Srinivasagam S (1982) An instance of large scale parasitism of Heterosaccus dollfusi Boschma on the edible crab, Portunus sanguinoletus (Herbst) in Pulicat Lake. J Inland Fish Soc India 14:88-90

Veillet A (1945) Recherches sur le parasitisme des crabes et des Galathées par les Rhizocéphales et les épicarides. Ann I Océanogr Paris 22:193-341

Veillet A, Graf F (1958) Dégénérescence de la glande androgène des Crustacés décapodes parasités par les Rhizocéphales. Bull Mens Soc Sci N 18:123-127

Vernet-Cornubert G (1958) Recherches sur la sexualité du crabe Pachygrapsus marmoratus (Fabricius). Arch Zool Exp Gén 96:101-276

Weng HT (1987) The parasite barnacle, Sacculina granifera Boschma, affecting the commercial sand crab, Portunus pelagicus (L.), in populations from two different environments in Queensland. J Fish Dis 10:221-227

Werner M (2001) Prevalence of the parasite Sacculina carcini Thompson 1836 (Crustacea, Rhizocephala) on its host crab Carcinus maenas (L.) on the west coast of Sweden. Ophelia 55:101-110

Yamaguchi T, Aratake H (1997) Morphological modifications caused by Sacculina polygenea in Hemigrapsus sanguineus (De Haan) (Brachyura: grapsidae). Crust Res 23:89-101 